\title{
Concrete Encased with Engineering Plastics
}

\author{
Nwzad Abduljabar Abdulla \\ College of Engineering, Salahaddin Univ., Kirkuk Rd., Erbil, Republic of Iraq \\ E-mail: anwzad@yahoo.com
}

Received: 1 August 2019; Accepted: 30 August 2019; Available online: 20 November 2019

\begin{abstract}
Engineering plastic tubes are economic alternatives for the advanced composite tubing systems. The mechanical behavior of concrete-encased with engineering plastic tube (CFPT) is examined in the present study by testing short-stub CFPT columns under concentric loading. The test parameters include the plastic tube and coarse aggregate/cement ratio (a/c) ratio. Due to the low stiffness of plastic tubes, the cementitious systems have an important role to increase the stiffness of CFPT. For making concrete of consistent strength, a/c ratio is an important criterion since aggregate constitutes more than $70 \%$ of concrete. The proportion of this major component of concrete was altered in increments of 0.5 resulting in twelve mixes with a/c ratios from 3 to 8 . Due to the limited test data, the mechanical performance of these structures continues to be pursued through experimental methods. The aim of the present study was to investigate experimentally the relationship between the strength of CFPT and $\mathrm{a} / \mathrm{c}$ ratio which is also affected by variations in other constituent materials. The $\mathrm{a} / \mathrm{c}$ ratio was the common variable in both control and CFPT specimens. The experimental results show that the ability of the engineering plastic tube in improving the load capacity of CFPT was considerably affected by the a/c ratio increment which yielded a beneficial effect on the tube confinement capacity.
\end{abstract}

Keywords: a/c ratio; Tubing systems; Concentric load; Encasement.

\section{Introduction}

In our modern society, some innovative and new materials, have been developed and applied in the field of civil and construction engineering. This has been driven by modern design necessity for persistent optimization of civil infrastructures in terms of both materials and structural components. Introducing innovative engineering plastics to form composites with concrete was first investigated by Kurt [1] and a new composite column system was proposed for structural applications. Due to its desirable characteristics, PVC is the most widely used plastics in civil applications. An alternative to the technique of using steel tube with concrete in-fill [2,3] is the concretefilled plastic tube (CFPT) with potential field applications in marine piles and bridge piers [4]. Due to the limited test data, the mechanical performance of these structures continues to be pursued through experimental methods. The experimental confinement capacity of PVC tube was shown to be approximately half of that of one ply of CFRP or GFRP [5]. Flexible thermoplastic tubes filled with concrete were tested under axial compression for a height/diameter (H/D) ratio of 0.5 to 4 [6]. The ductility index was increased by 1.56-3.39 times and the strain at peak stress by 1.54-5.04 times over that of unconfined concrete, depending on geometric slenderness, H/D ratio, and tube thickness. The lateral confinement of concrete core in composite was restricted by the tube stiffness, dramatically impairing its resistance to the transverse expansion of concrete core. However, large axial and lateral deformations were exhibited by the composite before failure.

To provide a stiffer plastic tube, FRP strips [7] or FRP wraps [8] were used externally to confine the tube resulting in a new type of hybrid column construction. However, regarding the elongation at break, plastic tubes are more reliable than the less ductile FRP tubes [9]. For making concrete of consistent strength, coarse aggregate/cement ratio $(\mathrm{a} / \mathrm{c})$ is an important criterion. The objective of the current study was to investigate experimentally the effect of a/c ratio on strength, ductility toughness ratio and axial load-strain relationship.

There is continuous interest in the usage of polymers in civil and construction applications. Engineering plastics are economic alternatives for the advanced composite tubing systems. The use of slender CFPT for light-weight structural applications was found feasible [10]. Other studies highlighted the potential use of plastic tube as an alternative for steel in piles [4]. The polymeric tube can be considered as a superelastic material [11] with little volume changes in parallel with large deformation and displacement. It has the capacity to eliminate shrinkage and temperature cracks and can be used in an aggressive environment due to its anti-corrosion characteristics. Short CFPT specimens tested under compression yielded 1.18 to 3.65 time's higher strength over the strength of unconfined specimens. This was ascribed to the composite interaction between the tube and concrete [12]. Three 
types of polymeric tubes, HDPE, PVC, and UPVC, were tested under axial load. Due to the confinement effect, strength increase of $6 \%, 19.43 \%$, and $39.54 \%$ was reported for the three types over that of unconfined concrete [13].

In an experimental work, the performance of plastic tube (HDPE)-confined self-consolidating concrete under different environmental exposure conditions was examined [14]. A 30\% increase in tube thickness yielded up to $50 \%$ higher fracture energy. Plastic tube externally reinforced with polyester fibers were used to improve the strength and ductility of RA specimens tested under uniaxial compression [15]. The composite tube confinement yielded $4.5 \%$ to $39.6 \%$ increase in strength accompanied by substantial axial deformation of the RA, ascribed to the much larger tensile strain of the polyester fibers and PVC material.

The potential utilization of PVC as an inner tube replacement for steel in double skinned hollow concrete-filled steel tubular columns DSHCFT was verified and found feasible for moderate load conditions [16]. In another study, the effects of shapes of PVC inner tube on the structural behavior of steel-concrete-PVC SHS joints under axial compression were evaluated [17]. Another practical use of the composite in civil engineering applications is to build prefabricated houses. As a part of the Global Housing Solutions technology in Latin America, the surface areas of the prefabricated houses were constructed of robust PVC to resist the high wind speeds. A recent hurricane has hit the region of construction and the houses were totally exposed to the forces of the natural disaster and withstood the catastrophe entirely undamaged [18]. PVC tube and CFRP-PVC tube confinement could improve the axial compression performance of RAC more effectively than NAC [19].

\section{Materials}

\subsection{Plastic tube}

The tubes were cut to the required sizes using an electrical sawing machine, Fig. 1. Coupons were prepared for tensile tests of the UPVC type polymeric tube, Fig. 2. Mechanical properties of the plastic tubes were determined from tests on two hollow tubes and two coupons (as per ASTM D638) [20] and the results were tabulated in Table 1 .

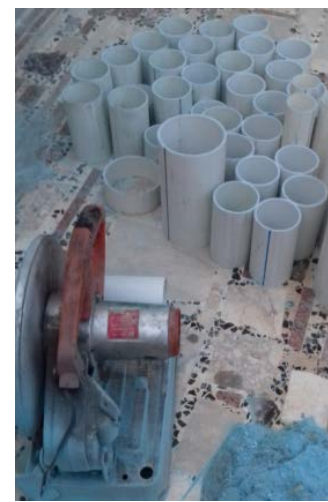

Fig.1. Cutting of plastic tube

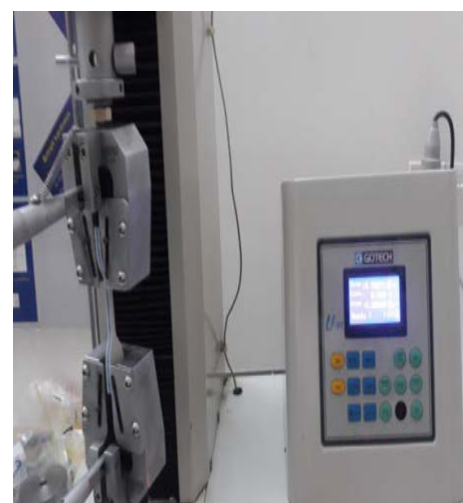

Fig. 2. Coupon tests

Table 1. Mechanical properties of plastic coupons and hollow tube

\begin{tabular}{llllll}
\hline specimen & $\begin{array}{l}\text { Yield strength } \\
\text { fy }(\mathrm{MPa})\end{array}$ & $\begin{array}{l}\text { Tensile strength } \\
\text { fu }(\mathrm{MPa})\end{array}$ & $\begin{array}{l}\text { Compression strength } \\
(\mathrm{MPa})\end{array}$ & $\begin{array}{l}\text { Poisson ratio } \\
\text { Elongation at break } \\
\%\end{array}$ \\
\hline 1 & 40 & 57.3 & - & 0.41 & 35 \\
2 & 40.1 & 57.2 & - & 0.41 & 35 \\
3 & $41^{*}$ & & $56.8^{*}$ & - & 36.2 \\
4 & $40.9 *$ & $56.5^{*}$ & - & 35.9 \\
\hline
\end{tabular}

\subsection{Concrete}

Well, graded river sand and coarse aggregate with a maximum aggregate size of $20 \mathrm{~mm}$, hydraulic cement, and the required water were mixed in a drum-type laboratory concrete mixer. By adjusting the a/c ratio from 3 to 8 (in increments of 0.5 ) seventy-six specimens were prepared from twelve concrete batches. The details of all the mixes were summarized in Table 2.

\subsection{CFPT specimens}

Each group had three specimens identical to each other. The purpose of the triplication was to check the quality 
and response of similar specimens. The specimen's designation is shown in Table1, where CT stands for CFPT and letters $\mathrm{A}$ to $\mathrm{K}$ for numbering of each group according to a/c ratio. In addition, each group had three $100 \mathrm{~mm}$ by $200 \mathrm{~mm}$ references specimens with no plastic tube to study the tube effect. On the day of testing, the specimens were capped with a special powder, Fig.3.

Table 2. Mix details and strength of concrete and CFPT.

\begin{tabular}{|c|c|c|c|c|c|c|}
\hline Specimen & Mix ratio & w/c ratio & a/c ratio & $f_{C O} \mathrm{MPa}$ & $f_{C E x}$ & $f_{C E \mathrm{X}} / f_{C O}$ \\
\hline CT-A1 & $1: 2: 1$ & 0.435 & 3.0 & 38.7 & 47.21 & 1.22 \\
\hline CT-A2 & $1: 2: 1$ & 0.435 & 3.0 & 38.7 & 48.38 & 1.25 \\
\hline CT-A3 & $1: 2: 1$ & 0.435 & 3.0 & 38.7 & 47.60 & 1.23 \\
\hline CT-B1 & $1: 2: 1.5$ & 0.450 & 3.5 & 37.2 & 46.13 & 1.24 \\
\hline CT-B2 & $1: 2: 1.5$ & 0.450 & 3.5 & 37.2 & 46.50 & 1.25 \\
\hline CT-B3 & $1: 2: 1.5$ & 0.450 & 3.5 & 37.2 & 47.62 & 1.28 \\
\hline CT-C1 & $1: 2: 2$ & 0.485 & 4.0 & 34.7 & 44.76 & 1.29 \\
\hline CT-C2 & $1: 2: 2$ & 0.485 & 4.0 & 34.7 & 44.42 & 1.28 \\
\hline CT-C3 & $1: 2: 2$ & 0.485 & 4.0 & 34.7 & 45.80 & 1.32 \\
\hline CT-D1 & $1: 2: 2.5$ & 0.505 & 4.5 & 32.9 & 41.45 & 1.26 \\
\hline CT-D2 & $1: 2: 2.5$ & 0.505 & 4.5 & 32.9 & 45.73 & 1.39 \\
\hline CT-D3 & $1: 2: 2.5$ & 0.505 & 4.5 & 32.9 & 44.42 & 1.35 \\
\hline CT-E1 & $1: 2: 3$ & 0.51 & 5.0 & 32.2 & 44.11 & 1.37 \\
\hline CT-E2 & $1: 2: 3$ & 0.51 & 5.0 & 32.2 & 45.08 & 1.40 \\
\hline CT-E3 & $1: 2: 3$ & 0.51 & 5.0 & 32.2 & 44.76 & 1.39 \\
\hline CT-F1 & $1: 2: 3.5$ & 0.51 & 5.5 & 31.2 & 42.43 & 1.36 \\
\hline CT-F2 & $1: 2: 3.5$ & 0.51 & 5.5 & 31.2 & 43.99 & 1.41 \\
\hline CT-F3 & 1:2:3.5 & 0.51 & 5.5 & 31.2 & 44.62 & 1.43 \\
\hline CT-G1 & $1: 2: 4$ & 0.52 & 6.0 & 28.6 & 40.04 & 1.40 \\
\hline CT-G2 & $1: 2: 4$ & 0.52 & 6.0 & 28.6 & 40.90 & 1.43 \\
\hline CT-G3 & $1: 2: 4$ & 0.52 & 6.0 & 28.6 & 40.46 & 1.40 \\
\hline CT-H1 & $1: 2: 4.5$ & 0.535 & 6.5 & 25.5 & 37.74 & 1.48 \\
\hline CT-H2 & $1: 2: 4.5$ & 0.535 & 6.5 & 25.5 & 38.51 & 1.51 \\
\hline СТ-Н3 & $1: 2: 4.5$ & 0.535 & 6.5 & 25.5 & 36.98 & 1.45 \\
\hline CT-I1 & $1: 2: 5$ & 0.56 & 7.0 & 20.4 & 31.42 & 1.54 \\
\hline CT-I2 & $1: 2: 5$ & 0.56 & 7.0 & 20.4 & 32.44 & 1.59 \\
\hline CT-I3 & $1: 2: 5$ & 0.56 & 7.0 & 20.4 & 32.03 & 1.57 \\
\hline CT-J1 & $1: 2: 5.5$ & 0.585 & 7.5 & 19.2 & 31.49 & 1.64 \\
\hline CT-J2 & $1: 2: 5.5$ & 0.585 & 7.5 & 19.2 & 31.49 & 1.64 \\
\hline CT-J3 & $1: 2: 5.5$ & 0.585 & 7.5 & 19.2 & 32.45 & 1.69 \\
\hline CT-K1 & $1: 2: 6$ & 0.6 & 8.0 & 16.7 & 29.39 & 1.76 \\
\hline CT-K2 & $1: 2: 6$ & 0.6 & 8.0 & 16.7 & 29.89 & 1.79 \\
\hline CT-K3 & $1: 2: 6$ & 0.6 & 8.0 & 16.7 & 29.22 & 1.75 \\
\hline CT-L1 & $1: 2: 6.5$ & 0.605 & 8.5 & 16.3 & 30.32 & 1.86 \\
\hline CT-L2 & $1: 2: 6.5$ & 0.605 & 8.5 & 16.3 & 29.99 & 1.84 \\
\hline CT-L3 & $1: 2: 6.5$ & 0.605 & 8.5 & 16.3 & 29.67 & 1.82 \\
\hline
\end{tabular}

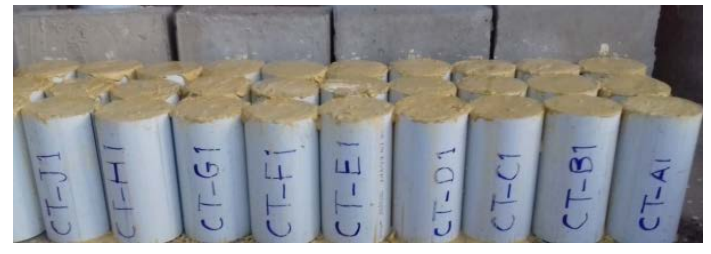

Fig. 3. Capping of CFPT

\section{Instrumentation and testing procedures}

Electrical strain gauges attached on the tube surface were used to determine longitudinal and lateral strains and the modulus of elasticity. Two transducers (LVDT) was attached next to the bottom plate and pointed at the upper plate of the testing machine to record the relative displacement between the two plates. Another two LVDT was 
used to measure the lateral displacement at mid-height. Specimens were tested using a $2500 \mathrm{kN}$ capacity hydraulic testing machine and the axial load was recorded with a load cell located at the bottom of the rigid subplate, Fig. 4. Wrinkle (outward bulge-type local buckle in the tube wall) was initiated at ultimate load-carrying capacity) formed near one end of the tube because of the presence of large stress concentrations (elephant foot). The tests on CFPT and reference specimens were carried out under displacement control. Triplicate specimens were tested for each test series.
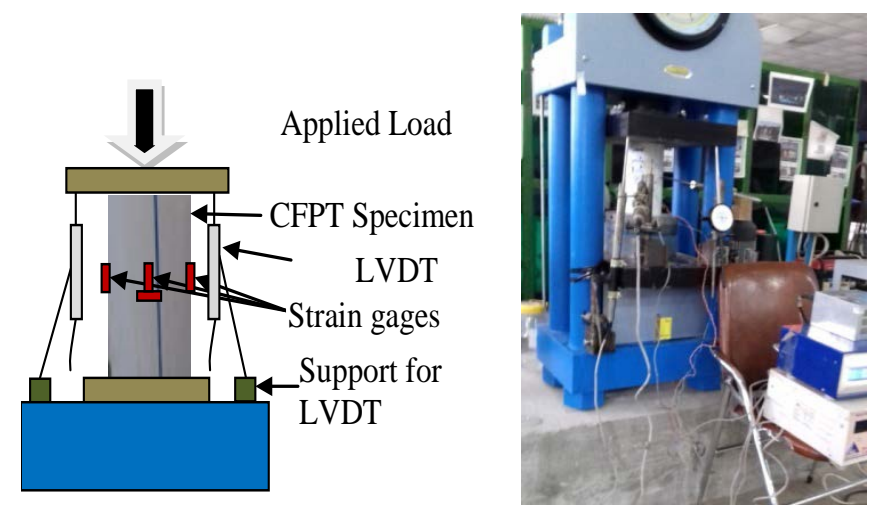

Fig.4. Test set up

In the elastic range of the loading procedure, each specimen was loaded at a rate of approximately $0.1 \mathrm{kN} / \mathrm{s}$. In the post-peak stage, displacement control was adopted with the hydraulic actuator driven at a constant rate of 0.5 $\mathrm{mm} / \mathrm{min}$. The 72 specimens were tested to failure under axial compression. In the elastic range of the loading (i.e. $\mathrm{N}<0.7 \mathrm{Nu}$, the behavior was similar. at $0.7 \mathrm{Nu}$, the specimens started to exhibit nonlinear behavior. At the peak load, no local buckling was observed for the plastic tube. When the applied load started to decrease the outward local buckling started at one location in the middle part. As the load was decreased several other local bulging plastic buckling were initiated at different locations. With a further decrease in load, the size of the bulging point was increased, Fig. 5.

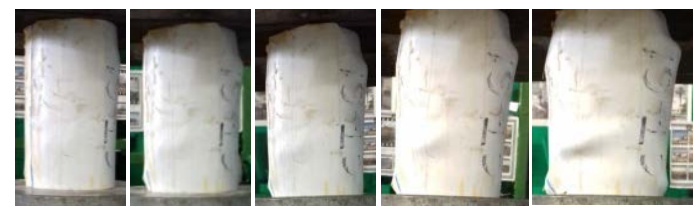

Fig.5. Gradual deformation of specimen CT-G1

After the testing, the tubes were cut along the height. The concrete core was crushed at zones located at the upper end and the mid-height of the concrete in-fill. It was observed that the specimen with higher a/c ratio exhibited more ductile behavior compared with specimens with lower a/c ratio. The three identical stub columns in each set showed good consistency in the experimental test results and the average value was adopted in the present investigation. Specimens with high a/c ratio exhibited more stable lateral deformation compared with specimens having lower a/c ratio.

\section{Discussions}

\subsection{Axial stress-strain response}

The stress-strain relationship of the CFPT specimens was plotted in Fig. 6 which features a relatively steady descending post-peak branch in sharp contrast to the reference specimens which failed without exhibiting any descending branch. Specimens behaved similarly in terms of the peak conditions and the trend of the compression softening of the second branch. The stress versus recorded axial deformation relationship for all the CFPT was plotted in Fig. 6, the companion reference specimens were excluded from the figure due its brittle failure were the curve has no falling branch. The curve for CFPT specimens can be simplified into three zones; elastic zone, elastoplastic phase, and plastic softening zone, Fig. 6.

In the elastic zone, the Poisson ratio of the concrete core was lower than that of the plastic tube at the beginning of the test. Hence, the change in circumferential compressive stress in the plastic tube was negligible (small increase followed by a decrease in the order of zero. The concrete in-fill dilation due to the vertical deformation was smaller than that of the plastic tube, which results in a trend of separation between the two. With further increase in the load, the concrete dilation increased and exceeded that of the plastic tube as a result of increased 
compression load. Thus the lateral compressive stress in the plastic tube decreased. In the second zone, the plastic tube becomes under circumferential tension, some confinement effects are initiated. Cracks are initiated and stretch rapidly in the concrete core.
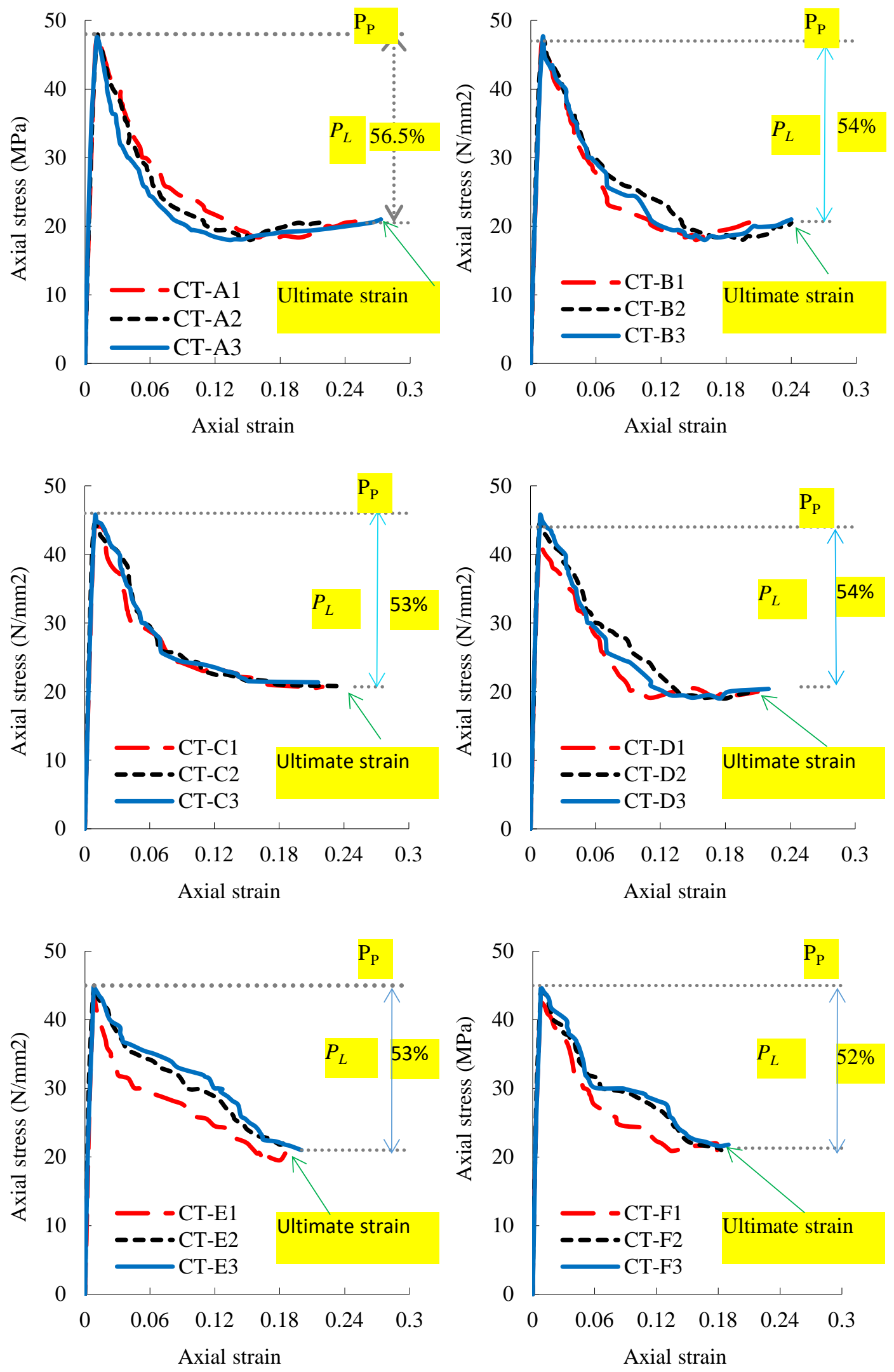

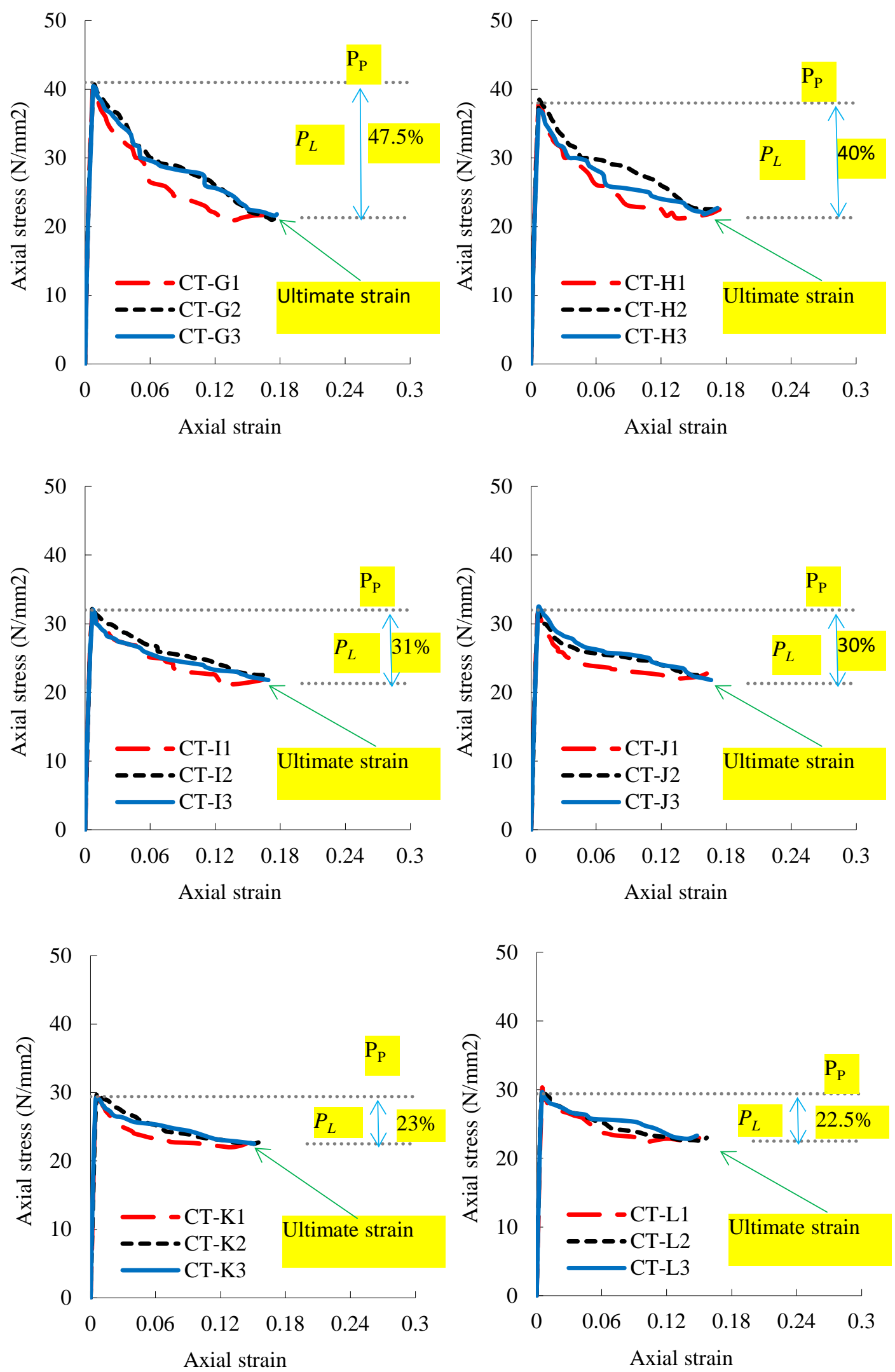

Fig. 6. Axial stress-strain relationship of all CFPT specimens

The ultimate strain had a decreasing trend with increasing a/c ratio. Significant increase in the ultimate strain $(\mathcal{E} u)$ was observed for specimens with higher a/c ratio. Due to the small wall thickness of plastic tube (small diametrical stress compared with that in the other two directions), it can be considered to be under plane stress 
condition. Kurtoglu et al. [14] after testing HDP concrete-filled HDP tubes observed descending or even ascending curve in the post-peak branch of load-deformation relationship depending on tube thickness.

The plastic tube exhibits considerable deformations in the plastic stage reaching almost $45 \%$ of elongation at break. When it encases the concrete this capacity is reduced to the brittle behavior of concrete. However, in the present study, the composite CFPT specimens were able to sustain nearly 30\% axial deformations (compression shortening) accompanied by nearly more than $10 \%$ expansion in the lateral direction before the failure, Fig. 7 . This resulted in a large area under the stress-strain diagram as was shown in Fig. 5.

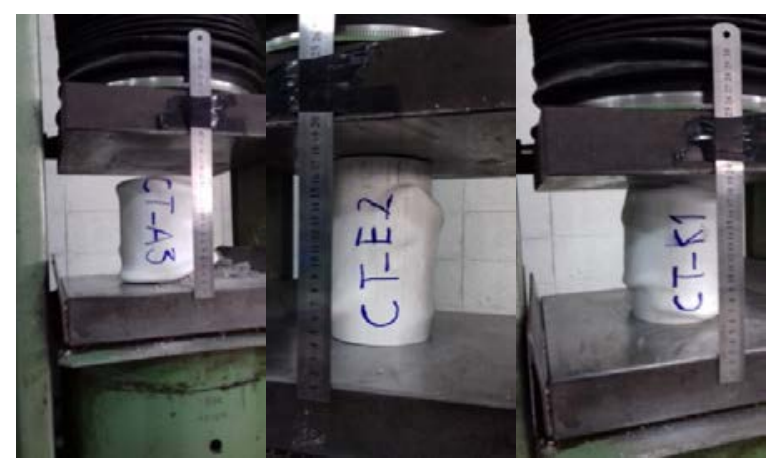

Fig. 7. Considerable plastic deformation prior to failure

\subsection{Confinement effect}

The confinement state of the external plastic tube changed during the loading process. In the initial elastic stage, the tube and concrete core displayed a similar increasing trend since the dilation of the concrete was small and the tube confinement has not yet been activated. After tube deformation, by plastic bulging, the concrete dilation increased due to the decrease in the stiffness of the post-yield plastic tube where the benefit of external tube confinement diminished steadily. The heterogeneity of the concrete-infill, responsible for the brittleness of concrete was partially restraint by the plastic tube. Confinement effects of the tube may also reduce the scatter of the maximum compressive load of control specimens. The engineering plastic confinement factor ranged from 0.12 to 0.3 .

In the residual stage, where the concrete core was totally confined by the plastic tube, the loss in the load ranged from 55 to $23 \%$ depending on a/c ratio, Fig. 5 . The plastic tube provided an almost constant or slightly increasing confining pressure after tube yielding due to the strain hardening. This shows that the higher a/c ratios reduce the load ratio corresponding to the initiation of the confinement effects. The concrete core with higher a/c ratio had higher elastic modulus and carried more load when the composite cross-section was under axial load which led to a larger transverse dilation of the concrete core, the initiation of the restraining action to the concrete core dilation provided by the plastic tube take place earlier with the increasing a/c ratio. The confinement effect increased the vertical peak stress in plastic tubes. When the axial stress in the plastic tube reached the peak value, the confinement effects became more pronounced, and the load of the concrete core further increased. The composite action between the tube and concrete core and no slippage at the interface between the two was important for the full activation of the light confinement mechanism of the tube.

\subsection{Ductility}

From the stress-strain diagram, the strain at yield, peak and at ultimate and the corresponding stresses were evaluated. The yield point and yield load was determined from the load-strain curve [21,22]. A chord line was drawn connecting the origin to the peak point, Fig. 8. A tangential line parallel to the chord intercepts the curve at the yield point. The results of the above approach were determined and summarized in Table 3 . The strain at failure is an indication of ductility and results in higher fracture energy. The deformation capacity was assessed by the ductility factors $\mathcal{E}_{\mathrm{p}} / \mathcal{E}_{\mathrm{y}}$ (ranging from 1.5 to 2 ) and $\mathcal{E} \mathrm{u} / \mathcal{E}_{\mathrm{y}}$ (ranging from 31 to 46 ).

\subsection{Energy absorption capacity}

Several authors used the load-axial deformation relationship to evaluate the energy dissipation capacity of compression members $[23,24]$. Under earthquake or wind loading, the energy dissipation capacity of the specimen is related to the area under the load-deformation diagram. To further characterize the strain-softening of CFPT, an ultimate strain corresponding to the failure strain $\left(\mathcal{E}_{\mathrm{u}}\right)$ was determined for the tested specimens. The area under the axial stress-strain curve represents the toughness of the composite specimen and can be evaluated as a toughness index (T.I.) pending on the resulting deformation. An ultimate strain of 0.015 was reported sufficient for evaluating the toughness of fiber concrete specimens under compression [25,26]. However, in the present study, 
its was not possible to adopt a strain 0.0154 to compute the toughness since most of the CFPT specimens still had residual strengths greater than $90 \%$ of the peak load at the above strain, since a rigid-flexible material was used to confine the concrete. Instead, a strain 0.12 was adopted, Fig.9, and the T.I was computed accordingly using the equation:

$$
\text { T.I. }=\frac{\text { Area } O A B C}{\left(P_{P}\right) 0.12}
$$

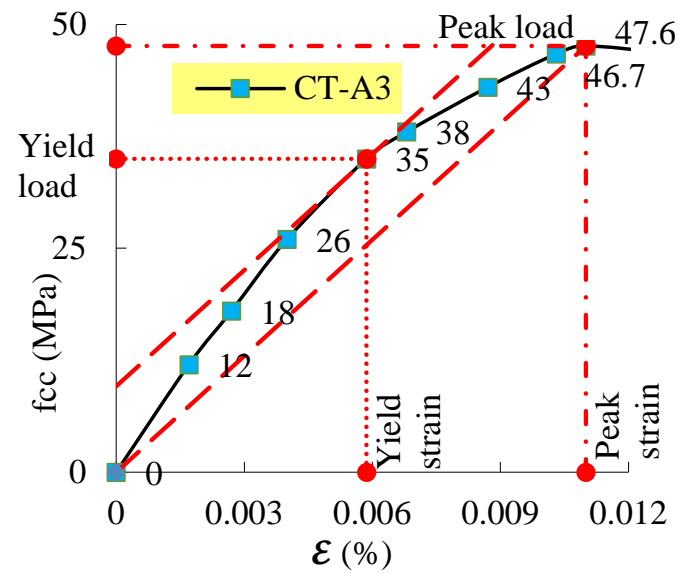

Fig. 8. Determination of yield point

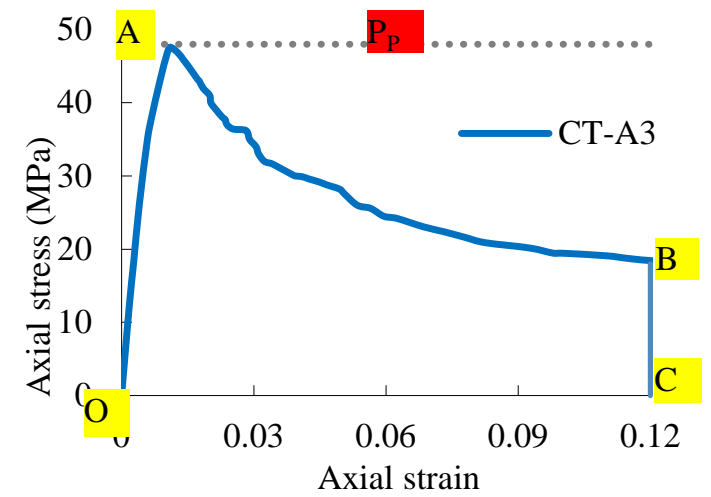

Fig. 9. Definition of (T.I.)

Table 3. Test results of CFPT columns

\begin{tabular}{|c|c|c|c|c|c|c|c|c|c|c|c|c|}
\hline Specimen & $\begin{array}{l}\mathrm{Py} \\
\mathrm{MPa}\end{array}$ & $\mathcal{E}_{\mathrm{y}}$ & $\begin{array}{l}\mathrm{PP}_{\mathrm{P}} \\
\mathrm{MPa}\end{array}$ & $\mathcal{E}_{\mathrm{p}}$ & $\begin{array}{l}\mu_{1} \\
\mathcal{E}_{\mathrm{p}} / \mathcal{E}_{\mathrm{y}}\end{array}$ & $\mathrm{P}_{\mathrm{p}} / \mathrm{Py}$ & $\begin{array}{l}\mathrm{Pu} \\
\mathrm{MPa}\end{array}$ & $\mathcal{E u}$ & $\mathrm{Pu} / \mathrm{py}$ & $\begin{array}{l}\mu_{2} \\
\mathcal{E}_{\mathrm{u}} / \mathcal{E}_{\mathrm{y}}\end{array}$ & Pre/PEx & T.I \\
\hline CT-A1 & 37 & 0.0071 & 47.6 & 0.0112 & 1.577 & 1.286 & 21 & 0.259 & 0.568 & 36.479 & 0.93 & 0.78 \\
\hline CT-A2 & 38 & 0.0072 & 48.38 & 0.0113 & 1.569 & 1.273 & 20.6 & 0.223 & 0.542 & 30.972 & 0.95 & 0.76 \\
\hline CT-A3 & 35 & 0.0058 & 47.6 & 0.011 & 1.877 & 1.360 & 21 & 0.273 & 0.6 & 46.587 & 0.93 & 0.74 \\
\hline CT-B1 & 35 & 0.0066 & 46.7 & 0.01 & 1.503 & 1.334 & 20.9 & 0.215 & 0.597 & 32.331 & 0.93 & 0.76 \\
\hline CT-B2 & 37.4 & 0.0068 & 47 & 0.0125 & 1.830 & 1.256 & 20.5 & 0.24 & 0.548 & 35.294 & 0.94 & 0.75 \\
\hline CT-B3 & 35 & 0.0070 & 47.62 & 0.0112 & 1.600 & 1.361 & 22.8 & 0.255 & 0.651 & 36.429 & 0.96 & 0.72 \\
\hline CT-C1 & 34 & 0.0062 & 44.76 & 0.0096 & 1.548 & 1.316 & 20.7 & 0.22 & 0.609 & 35.484 & 0.95 & 0.60 \\
\hline CT-C2 & 31 & 0.0051 & 44.42 & 0.0089 & 1.749 & 1.306 & 20.8 & 0.236 & 0.671 & 46.235 & 0.95 & 0.66 \\
\hline CT-C3 & 32 & 0.0056 & 45.8 & 0.0099 & 1.768 & 1.431 & 21.4 & 0.216 & 0.667 & 38.571 & 0.98 & 0.64 \\
\hline CT-D1 & 29.5 & 0.0050 & 41.45 & 0.0082 & 1.640 & 1.405 & 20 & 0.21 & 0.678 & 42 & 0.92 & 0.61 \\
\hline CT-D2 & 31.5 & 0.0061 & 44.42 & 0.0083 & 1.361 & 1.41 & 20 & 0.208 & 0.635 & 34.98 & 1.01 & 0.66 \\
\hline CT-D3 & 30 & 0.0049 & 45.8 & 0.009 & 1.837 & 1.526 & 20.4 & 0.22 & 0.68 & 44.898 & 0.99 & 0.69 \\
\hline CT-E1 & 30.7 & 0.0050 & 44.11 & 0.0081 & 1.634 & 1.437 & 20.5 & 0.185 & 0.668 & 37.373 & 0.99 & 0.72 \\
\hline CT-E2 & 31 & 0.0041 & 45.08 & 0.0086 & 2.097 & 1.454 & 21.5 & 0.19 & 0.694 & 46.341 & 1.02 & 0.75 \\
\hline CT-E3 & 29 & 0.0044 & 44.76 & 0.0081 & 1.841 & 1.543 & 21 & 0.2 & 0.724 & 45.454 & 1.01 & 0.69 \\
\hline CT-F1 & 28.9 & 0.0039 & 42.43 & 0.0077 & 1.949 & 1.468 & 21 & 0.179 & 0.727 & 45.316 & 0.98 & 0.76 \\
\hline CT-F2 & 30 & 0.0038 & 43.99 & 0.0079 & 2.079 & 1.466 & 21 & 0.183 & 0.7 & 48.158 & 1.01 & 0.75 \\
\hline CT-F3 & 30 & 0.0041 & 44.62 & 0.008 & 1.951 & 1.483 & 21.8 & 0.19 & 0.727 & 46.341 & 1.03 & 0.76 \\
\hline CT-G1 & 30 & 0.0040 & 40.04 & 0.0071 & 1.775 & 1.335 & 21.2 & 0.17 & 0.707 & 42.5 & 0.98 & 0.78 \\
\hline CT-G2 & 29.7 & 0.0041 & 40.9 & 0.0078 & 1.916 & 1.377 & 21.2 & 0.175 & 0.712 & 42.998 & 1.00 & 0.70 \\
\hline CT-G3 & 30 & 0.0040 & 40.46 & 0.0076 & 1.900 & 1.349 & 21.2 & 0.179 & 0.707 & 44.75 & 0.98 & 0.64 \\
\hline CT-H1 & 29.5 & 0.0043 & 37.74 & 0.007 & 1.628 & 1.279 & 22.5 & 0.174 & 0.763 & 40.465 & 1.00 & 0.73 \\
\hline CT-H2 & 28.5 & 0.0044 & 38.51 & 0.0073 & 1.659 & 1.351 & 22.4 & 0.168 & 0.786 & 38.182 & 1.02 & 0.68 \\
\hline СТ-H3 & 28 & 0.0042 & 36.98 & 0.0071 & 1.69 & 1.321 & 22.7 & 0.172 & 0.811 & 40.952 & 0.98 & 0.78 \\
\hline CT-I1 & 26 & 0.0044 & 31.42 & 0.0067 & 1.523 & 1.208 & 21.9 & 0.166 & 0.842 & 37.614 & 0.96 & 0.80 \\
\hline CT-I2 & 26 & 0.0046 & 32.44 & 0.0068 & 1.478 & 1.248 & 22.2 & 0.168 & 0.855 & 36.522 & 1.00 & 0.83 \\
\hline CT-I3 & 26 & 0.0047 & 32.03 & 0.007 & 1.489 & 1.232 & 21.8 & 0.169 & 0.838 & 35.957 & 0.98 & 0.76 \\
\hline CT-J1 & 25 & 0.0043 & 31.49 & 0.0061 & 1.418 & 1.259 & 22.8 & 0.162 & 0.91 & 37.674 & 1.00 & 0.80 \\
\hline CT-J2 & 25 & 0.0045 & 31.49 & 0.0064 & 1.422 & 1.259 & 22.4 & 0.16 & 0.896 & 35.555 & 1.00 & 0.82 \\
\hline CT-J3 & 26 & 0.0049 & 32.45 & 0.0067 & 1.367 & 1.248 & 21.8 & 0.166 & 0.838 & 33.877 & 1.03 & 0.81 \\
\hline CT-K1 & 25 & 0.0041 & 29.39 & 0.0055 & 1.341 & 1.175 & 22.9 & 0.149 & 0.918 & 36.34 & 1.02 & 0.80 \\
\hline CT-K2 & 25 & 0.0042 & 29.89 & 0.0059 & 1.405 & 1.195 & 22.7 & 0.155 & 0.908 & 36.905 & 1.03 & 0.82 \\
\hline CT-K3 & 23 & 0.0033 & 29.22 & 0.0052 & 1.600 & 1.27 & 22.5 & 0.151 & 0.979 & 46.462 & 1.01 & 0.83 \\
\hline CT-L1 & 24 & 0.0037 & 30.32 & 0.0052 & 1.405 & 1.263 & 22.9 & 0.15 & 0.956 & 40.541 & 1.06 & 0.83 \\
\hline CT-L2 & 25 & 0.0034 & 29.99 & 0.005 & 1.470 & 1.199 & 23 & 0.157 & 0.92 & 46.149 & 1.05 & 0.84 \\
\hline CT-L3 & 23 & 0.0034 & 29.67 & 0.0051 & 1.500 & 1.29 & 23.3 & 0.148 & 0.987 & 43.529 & 1.04 & 0.85 \\
\hline
\end{tabular}




\subsection{Strength}

Upon reaching the peak load, the control specimens exhibited a serious degradation in loading capacity and a total loss of strength in sharp contrast to the plastic tube which had enough stiffness to contain concrete dilation without tear or fracture and displaying a strain-softening post-peak response. Earlier research has shown the postpeak behavior of the CFPT to be significantly affected by the concrete strength [27]. The scatter of the maximum compressive load for reference specimens was relatively higher than that in the CFPT specimen. The contribution of the plastic tube to the strength of the composite specimen was a factor leading to such considerable reductions in the scatter of the test results. Strength enhancement increased as the in-fill concrete compressive strength decreased. The strength of specimens reduced modestly with the increasing ratio of a/c. for specimens with low a/c ratio, cracks extended to the aggregates as well as cement paste. For higher a/c ratios, cracks were running round the coarse aggregates particles due to the weak transition zone. Fig. 10 shows the developments of the strength enhancement ratio $f_{c c} / f_{c o}$ with different a/c ratios.

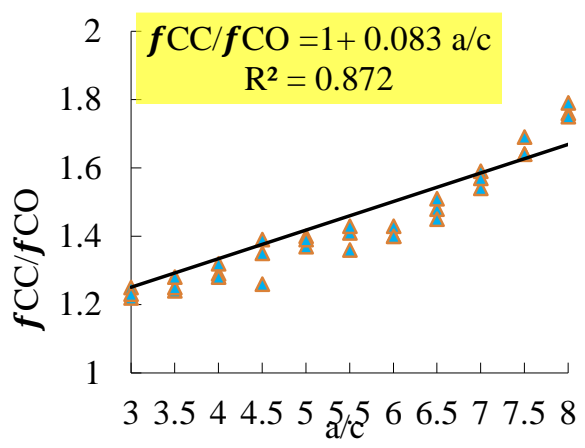

Fig. 10. $f_{c c} / f_{c o}$ versus $a / c$ ratio

\subsection{Analytical}

The proper design of these members is largely influenced by the predictability of the models. Previous research shows that existing models for FRP-confined concrete could be inadequate in one way or another for CFPT because not all essential factors are captured by the models. The proposed model can accurately apprehend the trends but it needs to be further developed in the future for higher accuracy pending on the availability of more test results. By adding the individual load-carrying capacities of the concrete in-fill and plastic tube, the axial load-carrying capacity of the CFPT was evaluated:

$N_{U}=f_{c c} A_{c}+f_{P} A_{P}$

A confinement index was introduced

$$
\xi_{P}=\left(\frac{f_{y P} A_{P}}{f_{u c} A_{c}}\right)
$$

Where $f_{y P}=$ yield strength of plastic tube; $A_{P}=$ cross-sectional area of plastic tube; $A c=$ area of concrete core. The relationship between $\xi$ and fcc/fco was shown in Fig. 10 yielding the following relationship:

$$
\frac{f_{c c}}{f_{c o}}=1+1.986 \xi_{P}
$$

Accordingly, hoop stress $\sigma_{l}$ can be calculated from the equation

$$
\sigma_{a}=\frac{\mathrm{P}-\frac{f_{c} \pi D^{2}}{4}}{\pi D t}=\sigma_{y p}=\text { tube yield stress }
$$

The predicted values using Eq. (4) were summarized in Table 3 showing good agreement with the experimental results. Fig. 11 depicts the development of $\xi$ with $f_{c c} / f_{c o}$. The influence of $a / c$ ratio on $\xi$ was plotted in Fig.12.

\section{Conclusions}

1) The CFPT specimens achieved a strength capacity that was approximately 1.22-1.86 times greater than the unconfined concrete strength. 


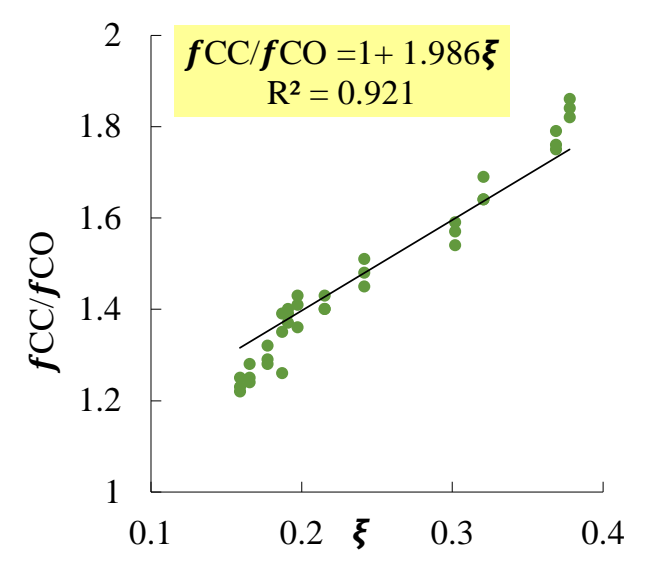

Fig. 11. Development of $\xi$ with $f_{c c} / f_{c o}$

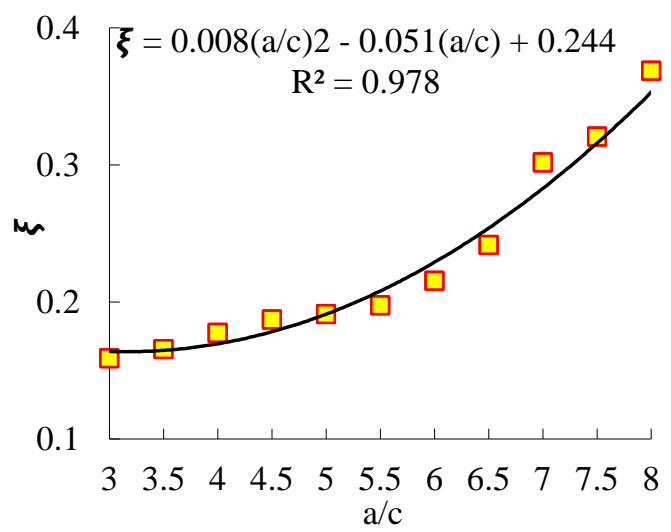

Fig. 12. Effect of $a / c$ ratio on $\xi$

2) a/c ratio affects the unconfined concrete strength level and the stress-strain curves.

3) The deformation capacity was assessed by the ductility factors $\varepsilon \mathcal{E}$ p/ $\mathcal{E}_{\mathrm{y}}$ (ranging from 1.5 to 2 ) and $\mathcal{E}_{\mathrm{u}} / \mathcal{E}_{\mathrm{y}}$ (ranging from 31 to 46).

4) In the post-peak zone or plastic zone, the specimen exhibit strain-softening since the tube confinement level degrades gradually and falls below the threshold value. Plastic tube promotes a ductile plateau in the axial stressstrain relationship of the falling branch. Near the failure the plastic tube exhibit some strain hardening but it is not sufficient to recover the full threshold confinement level experienced at the peak stress. The toughness index ranged from 0.6 to .85 which is an important factor for safe design.

Light-weight materials may play a vital role in the construction industry to support technological advances. Several studies have emphasized that the stiffness of the tube presents the most crucial parameter to influence the outcomes of the test results. The plastic tube is a useful protection tool for certain structures found near hostile environments due to its good corrosion resisting characteristics. CFPT is characterized by high ductility and this beneficial effect is a common phenomenon in such composite columns. Compared with the corrosive nature and low fire resistance of steel tubes, the better performance of plastic tubes, due to their material properties, may extend their use to seismic applications. Most of the researches on Plastic tube confined concrete were restricted to short specimens tested under uniaxial compression. New research should cover the eccentric loading of both short and long specimens. Additional tests are required to understand the performance of the composite system under lateral and flexural loads. More practical work, including field tests, and detailed information from analytical and experimental studies will be required for developing appropriate design guidelines. These measures will facilitate the introduction of the composite system in practice and civil construction works.

\section{References}

[1] Kurt EC. Concrete filled structural plastic columns. In:Proceedings ASCE104 ST1.1978; 1:55-63.

[2] Wang JZ, Cheng L, Sun ML, Jia JQ. Axial load behavior and strength of tube-confined steel-reinforced short columns with ultra-high-strength concrete. Advances in Structural Engineering. 2018; 21(3): 428-444.

[3] Tan Q, Gardner L, Han L, Song D. Analysis of concrete-filled stainless steel tubular columns under combined fire and loading. In: Proceedings of the 12th International Conference on Advances in Steel-Concrete Composite Structures. 2018. p. 825-833.

[4] Abdulla NA. Concrete filled PVC tube: A review. Construction and Building Materials. 2017;156:321-329.

[5] Fakharifar M, Chen G. Compressive behavior of FRP-confined concrete filled PVC tubular columns. Composite Structures. 2016; 141: 91-109.

[6] Abdulla NA. Concrete filled thermoplastic tube under compression. In: Proceedings of the $1^{\text {st }}$ international Engineering Conference on Developments in Civil and Computer Engineering Applications. University of Ishik, Erbil, Iraq. 2014. p.60-70.

[7] Toutanji H, Saafi M. Durability studies on concrete columns encased in PVC-FRP composite tubes. Composite Structures. 2001;54(1):27-35.

[8] Jiang S, Dai T, Fu D, Wu Z, Li N. Experimental study on concrete columns confined by BFRP-PVC tubes under uniaxial loading. Journal of Shenyang Jianzhu University (Natural Science). 2012; 28(1): $23-29$.

[9] Fakharifar M, Chen G. FRP-confined concrete filled PVC tubes: A new design concept for ductile column construction in seismic regions. Construction and Building Materials. 2017;130:1-10.

[10] Abdulla NA. Influence of plastic pour-in form on mechanical behavior of concrete. Structures. 2019; 19: 193202. 
[11] Jiang SF, Ma SL, Wu ZQ. Experimental study and theoretical analysis on slender concrete-filled CFRP-PVC tubular columns. Construction and Building Materials. 2014;53:475-487.

[12] Oyawa WO, Githimba NK, Mang'urio GN. Structural response of composite concrete filled plastic tubes in compression. Steel and Composite Structures. 2016;21(3):589-604.

[13] Karthikeyan N, Akshatha BA, Sudhesh AS, Basavaraja NH. Assessment of concrete cylinders confined with HDPE, PVC \& UPVC tubes. International Journal of Scientific \& Engineering Research. 2018; 9(4):83-77.

[14] Kurtoglu AE, Hussein AK, Gulsan ME, Altan MF, Cevik A. Mechanical investigation and durability of HDPE-confined SCC columns exposed to severe environment. KSCE Journal of Civil Engineering. 2018;22(12):5046-5057.

[15] Gao C, Huang L, Yan L, Jin R, Kasal B. Strength and ductility improvement of recycled aggregate concrete by polyester FRP-PVC tube confinement. Composites Part B: Engineering. 2019;162(1):178-197.

[16] Balasubramani N, Thenmozhi R. Strength and deflection of axially loaded DSHCFT column having PVC inner-steel outer pipes Annuarly in-filled with SCC M35. Indian Journal of Science and Technology. 2015; 8(S7):11-15.

[17] Chen Y, Feng R, Xiong L. Experimental and numerical investigations on steel-concrete-PVC SHS joints under axial compression. Construction and Building Materials. 2016;102:654-670.

[18] www.ghs-housing.com

[19] Lu JQ, Tian Y, Chen JG, Zhu CY, Zeng FY, Yang JC, Wang W. Experimental study on CFRP-PVC confined RAC under axial compression. In: Solid State Phenomena (Vol. 294). Trans Tech Publications Ltd; 2019. p.143-149.

[20] ASTMD638. Standard test method for tensile properties of plastics. West Conshohocken (PA): ASTM International; 2008.

[21] Feng P, Cheng S, Bai Y, Ye L. Mechanical behavior of concrete-filled square steel tube with FRP-confined concrete core subjected to axial compression. Composite Structures. 2015;123:312-324.

[22] Wang X, Qi Y, Sun Y, Xie Z, Liu W. Compressive behavior of composite concrete columns with encased FRP confined concrete cores. Sensors. 2019;19(8):1792.

[23] Tаo Z, Han LH, Zhuang JP. Axial loading behavior of CFRP strengthened concrete-filled steel tubular stub columns. Advances in Structural Engineering. 2007;10(1):37-46.

[24] Karimi K, Tait MJ, El-Dakhakhni WW. Influence of slenderness on the behavior of a FRP-encased steelconcrete composite column. Journal of Composites for Construction. 2012;16(1):100-109.

[25] Fanella DA, Naaman AE. Stress-strain properties of fiber reinforced mortar in compression. Journal Proceedings. 1985;82(4):475-483.

[26] Ezeldin AS, Balaguru PN. Normal-and high-strength fiber-reinforced concrete under compression. Journal of Materials in Civil Engineering. 1992;4(4):415-429.

[27] Bandyopadhyay A, Samanta AK, Michel Paul KJ. Assessment of axial capacity of RC stub column confined with unplasticized polyvinyl chloride pipe. Journal of the Institution of Engineers (India): Series A. 2019:112.

(C) 2019 by the author(s). This work is licensed under a Creative Commons Attribution 4.0 International License (http://creativecommons.org/licenses/by/4.0/). Authors retain copyright of their work, with first publication rights granted to Tech Reviews Ltd. 